\title{
Korelasi Antara Kecepatan Gelombang Geser dan NspT di Area Pulau Nuklir, Tapak RDE Serpong
}

\author{
Eko Rudi Iswanto*1, Theo Alvin Ryanto', Hadi Suntoko' \\ ${ }^{1}$ Pusat Kajian Sistem Energi Nuklir-BATAN \\ JI. Kuningan Barat, Mampang Prapatan, Jakarta 12710, Indonesia
}

\section{INFORMASI ARTIKEL}

Riwayat Artikel:

Diterima:

15 November 2021

Diterima dalam bentuk revisi:

30 Desember 2021

Disetujui:

30 Desember 2021

\section{Kata Kunci:}

Kecepatan Gelombang Geser $\mathrm{N}_{\mathrm{SPT}}$

Tapak

\begin{abstract}
ABSTRAK
KORELASI ANTARA KECEPATAN GELOMBANG GESER DAN N SPT $_{\text {DI AREA PULAU }}$ NUKLIR, TAPAK RDE SERPONG. Karakteristik gerakan tanah akibat gempabumi dipengaruhi oleh variasi nilai kecepatan gelombang geser $\left(V_{s}\right)$. Ketersediaan nilai $V_{s}$ suatu daerah belum tentu lengkap dan siap, hal ini disebabkan oleh penyelidikan langsung guna memperoleh nilai $\mathrm{V}_{\mathrm{s}}$ memerlukan waktu relatif lama dan biaya yang tidak sedikit. Selain itu juga dipengaruhi oleh tingkat keterjangkauan suatu daerah pengujian. Berbeda halnya dengan data jumlah pukulan $(\mathrm{N})$ dari uji Standard Penetration Test $\left(\mathrm{N}_{\mathrm{SPT}}\right)$ yang lebih banyak tersedia. Dewasa ini telah banyak dilakukan penelitian persamaan korelasi nilai $V_{s}$ dari data $\mathrm{N}_{\mathrm{SPT}}$, meskipun demikian tingkat keandalan antara satu dengan lainnya tidaklah sama. Studi ini bertujuan mengembangkan korelasi yang reliabel antara $V_{s}$ dan $N_{S P T}$ untuk kategori semua jenis tanah. Metode yang digunakan adalah dengan mengumpulkan dan menganalisis data hasil pengujian geofisika dan geoteknik kemudian melakukan analisis regresi non-linear. Dari hasil perhitungan diperoleh korelasi $\mathrm{V}_{\mathrm{s}}=98,759 \mathrm{~N}_{\mathrm{SPT}}{ }^{0,3101}$ untuk kategori semua jenis tanah di area pulau nuklir Tapak RDE, Serpong. Korelasi ini mampu memprediksi $V_{s}$ dengan cukup baik dan cepat, tanpa harus melakukan pengukuran yang memerlukan biaya lebih banyak dan waktu lebih lama.
\end{abstract}

\begin{abstract}

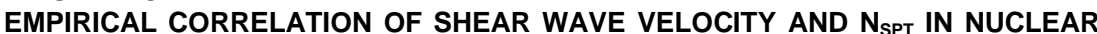
ISLAND AREA, THE RDE SITE SERPONG. The characteristics of ground motion due to earthquakes are affected by variations in the value of shear wave velocity $\left(V_{s}\right)$. The availability of $\mathrm{V}_{\mathrm{s}}$ for a specific region is not readily available due to direct investigation to obtain $V_{s}$, which takes a relatively long time and is costly. Moreover, some study areas have the unavailability of open space to conduct the test. On the other hand, the number of strokes $(\mathrm{N})$ data from the Standard Penetration Test $\left(\mathrm{N}_{\mathrm{SPT}}\right)$ is more widely available. Recently, many kinds of research on the correlation equation of $V_{S}$ from $N_{S P T}$ data have been carried out, although the level of reliability of the result is not similar. A reliable correlation equation between $V_{S}$ and $N_{S P T}$ for all soil types will be developed in this study. Data from geophysical and geotechnical testing results are collected and analyzed in a non-linear regression. The measurement method in the field and the amount of measurement data pose a challenge in obtaining an accurate correlation equation. The result is obtained in terms of a correlation equation defined as $\mathrm{V}_{S}=98,759 \mathrm{~N}_{\mathrm{SPT}}{ }^{0,3101}$ for the category of all types of soil in the nuclear island area RDE Site, Serpong. This correlation is able to estimate $V_{s}$ quite well and quickly without direct measurements that require more costs and time.

Keywords: Shear Wave Velocity, $\mathrm{N}_{\mathrm{SPT}}$, site
\end{abstract}

(C) 2021 Jurnal Pengembangan Energi Nuklir. All rights reserved

\section{PENDAHULUAN}

Izin tapak atas rencana pembangunan Reaktor Daya Eksperimental (RDE) telah disetujui Badan Pengawas Tenaga Nuklir (BAPETEN) pada Tahun 2017 setelah melalui tahapan evaluasi tapak. Lokasi tapak RDE berada di Serpong, Tangerang Selatan, Provinsi Banten seperti terlihat pada Gambar 1. Aspek kegempaan menjadi salah satu aspek yang harus dibuktikan keselamatan dan keterberimaannya [1-3].
Ketika terjadi gempabumi maka gelombang gempa akan menjalar dari sumber gempa menuju segala arah hingga ke permukaan yang akan dirasakan sebagai getaran tanah. Selama proses penjalaran, gelombang gempa akan mengalami penguatan gelombang (amplifikasi) atau pelemahan gelombang (deamplifikasi) tergantung medium yang dilalui. Sedangkan untuk tingkat getaran dipengaruhi dua faktor utama yaitu kekerasan litologi dan ketebalan sedimen bawah permukaan. 


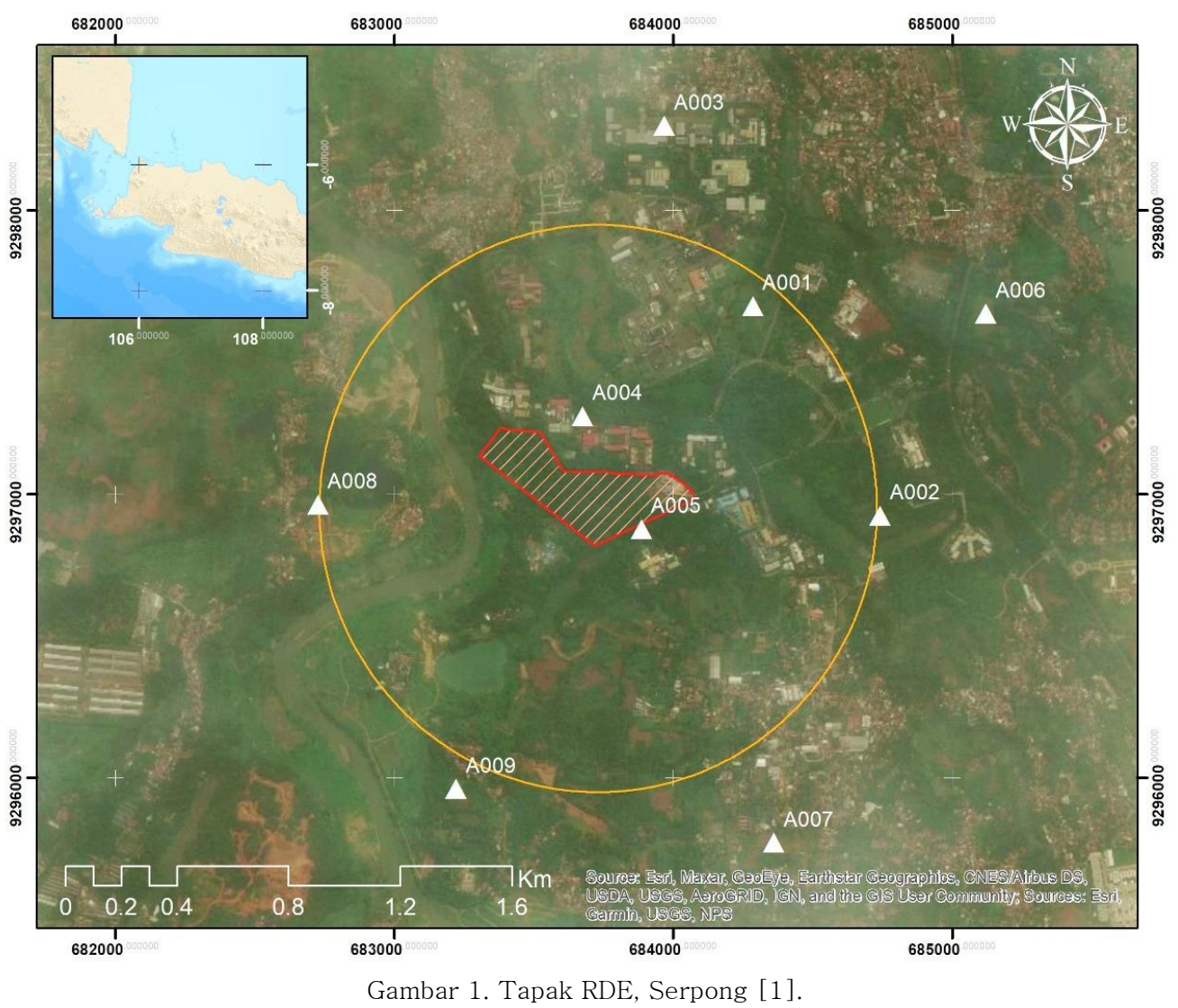

Parameter tanah menunjukkan kondisi bawah permukaan dapat dijadikan indikator untuk mengetahui besaran amplifikasi maupun deamplifikasi. Parameter tanah yang dimaksud yaitu kecepatan gelombang geser $\left(\mathrm{V}_{\mathrm{s}}\right)[5]$. Beberapa metode pengukuran langsung di lapangan telah banyak dikenal yang ditujukan untuk mengukur $V_{s}$. Pengukuran secara langsung dapat dilakukan melalui investigasi geofisika seperti Sesimic Down Hole (SDH) dan Microtremor Array Measurement (MAM) [4],[6],[2].

Namun demikian pengukuran secara langsung tidak dapat dilakukan, hal ini dapat disebabkan oleh ketidakcukupan ruang untuk pelaksanaan pengukuran. Bahkan apabila lokasi penelitian berada di pemukiman padat penduduk sangat tidak memungkinkan karena adanya isu kebisingan[7]. Sehingga karakterisasi tapak dengan pengukuran secara langsung melalui investigasi geofisika tersebut akan banyak terkendala [8],[9]. Telah banyak dikembangkan penelitian tentang korelasi antara $V_{S}$ dan $N_{S P T}$ secara tidak langsung diberbagai negara. Seperti halnya pengembangan korelasi $\mathrm{V}_{\mathrm{S}}$ dan $\mathrm{N}_{\mathrm{SPT}}$ di Teheran dan Tiongkok yang mempertimbangkan umur geologi dan tipe tanah, [10], [11]. Hal ini dilakukan dengan menggunakan pendekatan korelasi empiris parameter tanah dari hasil pengujian dilapangan. Tujuan dari penelitian ini adalah untuk mengembangkan korelasi empiris antara $V_{s}$ dengan $N_{S P T}$ yang pada penelitian sebelumnya belum pernah dilakukan. Sehingga kedepan diharapkan nilai $\mathrm{V}_{\mathrm{s}}$ daerah kajian akan jauh lebih mudah diestimasi. Nilai $\mathrm{V}_{\mathrm{s}}$ diperoleh dari hasil investigasi geofisika MAM sedangkan nilai $\mathrm{N}_{\text {SPT }}$ berasal dari uji SPT yang dilakukan bersamaan dengan investigasi geoteknik yang berupa pemboran geoteknik dari penelitian sebelumnya [1].

\section{METODE}

Penelitian ini menggunakan metode (Gambar 2) yang terdiri dari tiga tahap. Tahap pertama berupa kegiatan pengumpulan data. Data yang dikumpulkan berupa data sekunder hasil pengujian SDH, data primer pengukuran MAM dan data sekunder hasil uji mekanika tanah dari pemboran geoteknik.

Kemudian dilanjutkan ketahap kedua yaitu kegiatan analisis. Pada tahap ini didahului 
dengan penggambaran kurva $\mathrm{V}_{\mathrm{s}}$ dari dua metode pengujian dan pengukuran kedalam satu kurva sehingga didapat keterdekatan $\mathrm{V}_{\mathrm{s}}$. Hal ini dilakukan karena perbedaan hasil $\mathrm{V}_{\mathrm{s}}$ seringkali dijumpai seiring dengan perbedaan metode dan alat yang dipergunakan. Sejalan dengan didapatkan parameter $\mathrm{V}_{\mathrm{s}}$, dari hasil uji Standard Penetration Test (SPT) akan diperoleh parameter jumlah pukulan (N) yang kemudian disingkat $\mathrm{N}_{\mathrm{SPT}}$. Nilai $\mathrm{N}_{\mathrm{SPT}}$ dari hasil pengujian akan dikoreksi dan hasilnya akan dibandingkan pada saat pengembangan korelasi empirik.

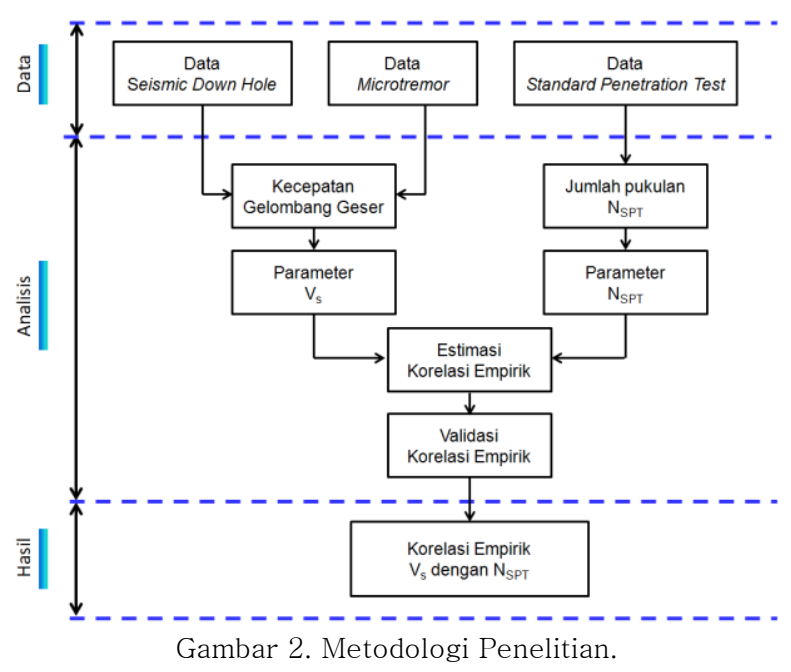

Langkah selanjutnya estimasi korelasi empirik berdasarkan kedua parameter tersebut dapat dihitung untuk kemudian hasilnya divalidasikan dengan korelasi empirik hasil penelitian-penelitian sebelumnya. Sehingga pada tahap ketiga atau akhir diperoleh hasil berupa korelasi empirik untuk kategori semua jenis tanah di area pulau nuklir Tapak RDE, Serpong.

\subsection{Seismic Down Hole (SDH)}

Pengujian SDH dilaksanakan berdasarkan ASTM D7400-08[12]. Peralatan yang dipakai berupa geophone triaksial, perekam dan martil pemukul sumber getaran seperti ditunjukkan dalam Gambar 3. Geophone triaksial berupa probe SDH merk OYO model 3315 dan alat perekam berupa seismic recorder model seistronix RAS-24. Prinsip kerja dari SDH adalah sumber getaran diletakkan di permukaan tanah dan dekat dengan lubang bor, sedangkan geophone sebagai receiver atau sensor penerima yang kemudian diletakkan pada berbagai variasi kedalaman dimasukkan kedalam lubang bor. Sensor penerima dihubungkan dengan sistem pencatat, sehingga semua output dapat diukur sebagai fungsi waktu. Waktu perambatan gelombang ini yang kemudian diplot dan selanjutnya akan digunakan dalam perhitungan $\mathrm{V}_{\mathrm{s}}$ [13]

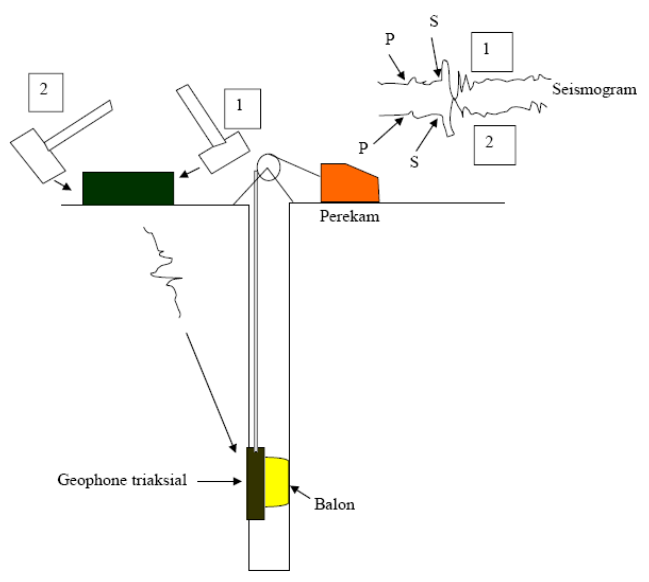

Gambar 3. Diagram survei tes SDH [1].

\subsection{Microtremor Array Measurement. (MAM)}

MAM dilakukan dengan memanfaatkan getaran alam atau lingkungan sekitar daerah studi yang bersifat tetap dengan sumber energi yang dapat berasal dari aktivitas manusia dengan frekuensi $\mathrm{f} \geq 1 \mathrm{~Hz}$ atau juga kejadian alam dengan frekuensi $\mathrm{f} \leq 1 \mathrm{~Hz}$. Beberapa metode pengolahan dewasa ini telah diterapkan diantaranya adalah Spatial Autocorrelation atau Spatially Averaged Coherency Spectra Method (SPAC), Frequency-wavenumber Method (FK) atau Multiple Signal Classification Method (MUSIC) [14-16]. Sebagai ilustrasi konfigurasi alat pada pengukuran dengan metode SPAC dapat dilihat pada Gambar 4.

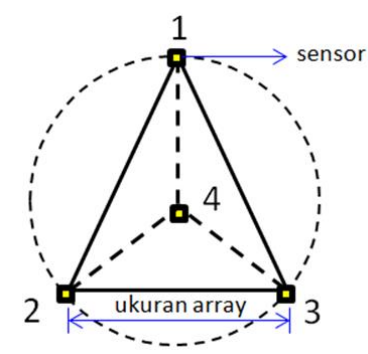

Gambar 4. Konfigurasi array pada MAM Metode SPAC [2].

Terdapat beberapa macam konfigurasi alat, yaitu mulai dari array linier, array bentuk 
L, array bentuk segitiga hingga array bentuk lingkaran. Dengan beberapa pertimbangan yang diantaranya adalah jumlah alat dan kondisi lokasi penelitian, maka pada penelitian ini dipilih konfigurasi alat menggunakan array bentuk segitiga dimana satu sensor triaxial diletakkan ditengah dengan radius $r$, sedangkan tiga sensor single axial mengelilinginya dengan bentuk segitiga. Besarnya resultan dari kurva percepatan gelombang geser dapat dicari di pusat segitiga (tengah).

\subsection{Standard Penetration Test (SPT)}

Geoteknik salah satunya mempelajari parameter-parameter desain tanah yang berkorelasi dengan nilai SPT [17], [18]. Dalam pengujian SPT pada umunya dilakukan bersamaan dengan pemboran geoteknik. Pelaksanaannya mengacu pada prosedur ASTM D-1586 [19]. Perlawanan tanah terhadap penetrasi tabung baja belah (raimond sampler) dinyatakan dengan nilai $\mathrm{N}_{\mathrm{SPT}}$. Jumlah pukulan untuk setiap usaha memasukkan tabung split spoon barrel sedalam $30 \mathrm{~cm}$ merupakan nilai $\mathrm{N}_{\text {SPT }}$. Pelaksanaan pengujian adalah sebagai berikut jumlah pukulan untuk memasukkan raimond sampler sedalam $15 \mathrm{~cm}$ pada tahap pertama dicatat sebagai dudukan awal. Kemudian dilanjutkan dengan jumlah pukulan untuk memasukkan raimond sampler sedalam $30 \mathrm{~cm}$ pada tahap kedua dan ketiga dijumlahkan untuk memperoleh nilai $\mathrm{N}_{\mathrm{SPT}}$. Pengujian dihentikan apabila diperlukan 50 jumlah pukulan untuk setiap penambahan penurunan $15 \mathrm{~cm}$ atau diperlukan 100 jumlah pukulan namun tidak terjadi penurunan. Biasanya pengujian dilakukan dengan interval tertentu seperti 2 $3 \mathrm{~m}$.

\section{HASIL DAN PEMBAHASAN}

Data sekunder yang digunakan pada penelitian ini merupakan data hasil pengukuran langsung pengujian SDH dan data primer dari pengukuran MAM. Secara umum, parameter $V_{\mathrm{s}}$ dari pengukuran MAM mempunyai kecenderungan yang sama apabila dibandingkan dengan parameter $\mathrm{V}_{\mathrm{s}}$ dari hasil pengujian SDH [2].

Pemboran geoteknik telah dilakukan pada penelitian sebelumnya di tapak RDE sebanyak
25 titik bor. Khusus pada penelitan ini digunakan dua titik bor di area pulau nuklir yaitu DH 11 dan DH 12 dengan beberapa pasang data NSPT digunakan dalam analisis selanjutnya.

Gambar 5 menunjukkan variasi banyaknya pukulan $\left(\mathrm{N}_{\mathrm{SPT}}\right)$ dengan kedalaman dari hasil pengujian SPT di titik bor DH 11 dan DH 12. Kedua lokasi memiliki kemiripan hasil yang mana $\mathrm{N}_{\mathrm{SPT}}$ cenderung kecil dari permukaan tanah hingga kedalaman sepuluh meter.
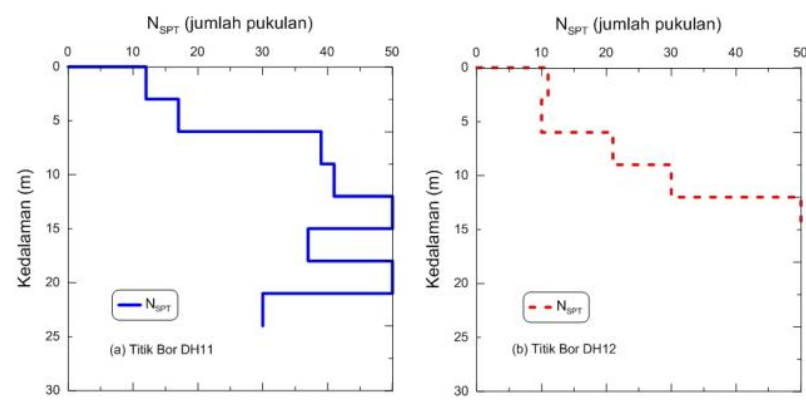

Gambar 5. Variasi NSPT dengan kedalaman untuk (a) Titik Bor DH 11 dan (b) Titik Bor DH 12.

Gambar 6 menunujukkan hasil SDH di titik bor DH 11 dan DH 12 berupa variasi nilai $V_{s}$ dari permukaan tanah hingga kedalaman $30 \mathrm{~m}$. Dapat dicermati dari dua data ini bahwa hingga kedalaman $15 \mathrm{~m}$ tidak ada variasi yang mencolok pada nilai $V_{s}$ dengan berbagai kedalaman. Pada titik bor DH11 maupun DH12 nilai $V_{\text {s }}$ relatif kecil yaitu diangka $<350 \mathrm{~m} / \mathrm{dt}$. Nilai ini berkesesuaian dengan nilai $\mathrm{N}_{\text {SPT }}$ yang juga relatif kecil.
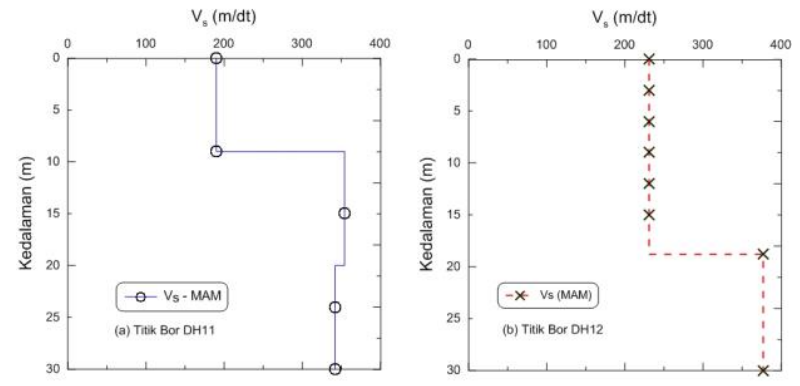

Gambar 6. Variasi nilai $\mathrm{V}_{\mathrm{s}}$ dengan kedalaman (a) Titik Bor DH 11 dan (b) Titik Bor DH 12.

Hubungan empiris antara $V_{\mathrm{s}}$ dengan nilai $\mathrm{N}_{\text {SPT }}$ dari hasil studi sebelumnya untuk semua jenis tanah, ditunjukkan pada Tabel 1. Pada penelitian ini dilakukan pengembangan korelasi tanpa koreksi dan dengan koreksi atas parameter $V_{\mathrm{s}}$ maupun parameter $\mathrm{N}_{\mathrm{SPT}}$ untuk semua jenis tanah. Korelasi antara parameter 
$\mathrm{V}_{\mathrm{s}}$ dan parameter $\mathrm{N}_{\mathrm{SPT}}$ dituliskan kedalam bentuk yang disajikan pada Persamaan 1 [20] sebagai berikut:

$$
V_{s}=a N^{b}
$$

Korelasi ini dikembangkan dengan analisis regresi sederhana dari persamaan korelasi empiris penelitian sebelumnya [20]. Gambar 7 menunjukkan estimasi $V_{\mathrm{S}}$ sebagai fungsi $\mathrm{N}_{\mathrm{SPT}}$ untuk semua jenis tanah di titik bor DH11 dengan menggunakan korelasi dari hasil penelitian sebelumnya. Pada umumnya korelasi yang ada dihitung mengunakan parameter $\mathrm{N}_{\mathrm{SPT}}$ tanpa koreksi, namun demikian beberapa korelasi juga dihitung dengan koreksi karena perbedaan alat dan metode pelaksanaan

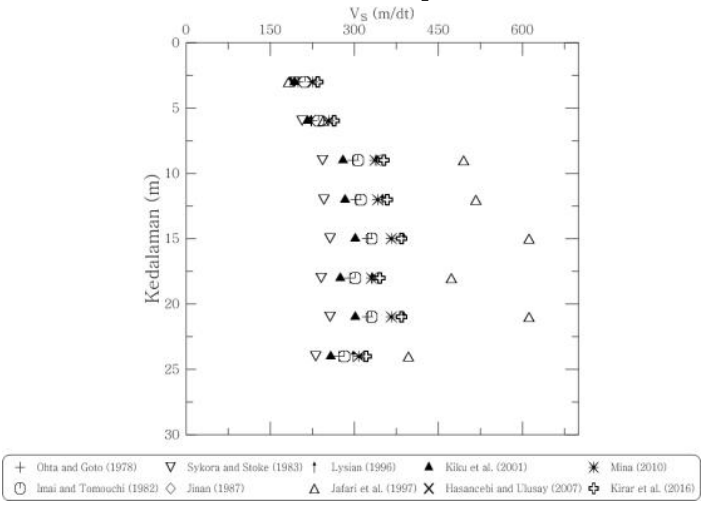

Gambar 7. Estimasi $V_{s}$ sebagai fungsi $N_{\text {SPT }}$ untuk semua jenis tanah di titik bor DH11 dengan menggunakan korelasi dari hasil penelitian sebelumnya (Gambar 5).

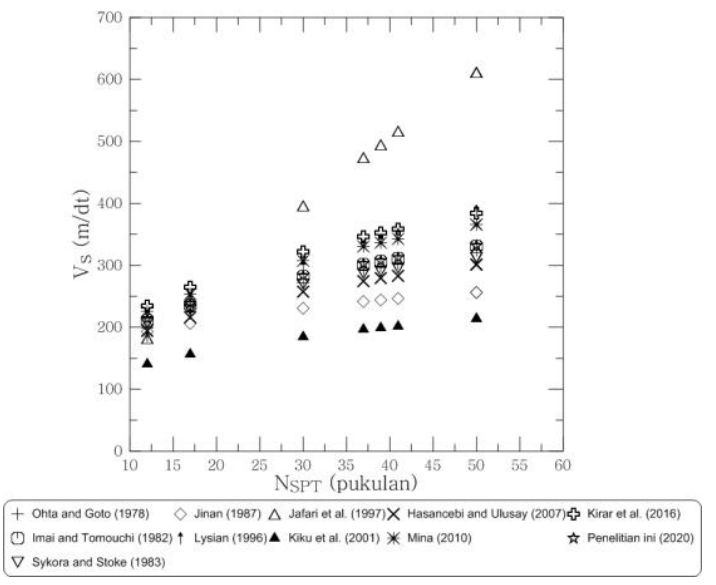

Gambar 8. Korelasi $\mathrm{V}_{\mathrm{s}}$ dan NsPT untuk semua jenis tanah dengan menggunakan korelasi dari hasil penelitian sebelumnya (Tabel 1) [20]dan penelitian sekarang.

Gambar 8 menunjukkan sebaran korelasi antara $\mathrm{V}_{\mathrm{S}}$ dan $\mathrm{N}_{\mathrm{SPT}}$ dari berbagai macam penelitian. Sebaran tersebut menggambarkan akan keberagaman karakteristik kondisi bawah permukaan daerah penelitian. Tantangan besar untuk mendapatkan prediksi korelasi yang lebih akurat, hal ini dapat diatasi dengan melakukan penyelidikan tambahan lainnya. Dapat diamati bahwa korelasi penelitian Jafari et al. menjadi batas atas sedangkan korelasi penelitian Kiku et al. menjadi batas bawah dari semua korelasi yang ada. Korelasi lainnya berada diantara Jafari et al. dan Kiku et al [10]. Korelasi penelitian Ohma and Goto, Imai and Tomouchi, Sykora and Stoke, dan Hasancebi and Ulusay cukup berkesesuaian, yang ditandai dengan kesamaan pola korelasi[21]. Hal serupa juga dapat dilihat pada korelasi penelitian Mina dan penelitian Kirar et al [22], [20]. Lebih lanjut pada penelitian Mina dengan lokasi penelitian di daerah Jakarta maka dari segi lokasi dapat dikatakan berdekatan dengan lokasi penelitian sekarang. Adanya beberapa faktor seperti jumlah, prosedur pengujian geoteknik maupun geofisika dan perbedaan kondisi bawah permukaan diduga menjadi penyebab ketidaksamaan korelasi.

Tabel 1. Korelasi empiris antara Vs dengan nilai $\mathrm{N}_{\text {SPT }}$ dari hasil studi sebelumnya [20]

\begin{tabular}{|c|c|c|c|}
\hline No. & Penulis & Tahun & Korelasi Empiris \\
\hline 1 & $\begin{array}{l}\text { Ohta and } \\
\text { Goto }\end{array}$ & 1978 & $\mathrm{~V}_{\mathrm{S}}=85,3 \mathrm{~N}^{0,341}$ \\
\hline 2 & $\begin{array}{l}\text { Imai and } \\
\text { Tonouchi }\end{array}$ & 1982 & $\mathrm{~V}_{\mathrm{S}}=96,9 \mathrm{~N}^{0,314}$ \\
\hline 3 & $\begin{array}{l}\text { Sykora and } \\
\text { Stoke }\end{array}$ & 1983 & $\mathrm{~V}_{\mathrm{S}}=100,5 \mathrm{~N}^{0,29}$ \\
\hline 4 & Jinan & 1987 & $\begin{array}{l}V_{S}=116,1 \\
(N+0,3185)^{0,202}\end{array}$ \\
\hline 5 & Lysian & 1996 & $\mathrm{~V}_{\mathrm{S}}=51,5 \mathrm{~N}^{0,516}$ \\
\hline 6 & Jafari et al & 1997 & $\mathrm{~V}_{\mathrm{S}}=22 \mathrm{~N}^{0,85}$ \\
\hline 7 & Kiku et al & 2001 & $\mathrm{~V}_{\mathrm{S}}=68,3 \mathrm{~N}^{0,292}$ \\
\hline 8 & $\begin{array}{l}\text { Hasancebi } \\
\text { and Ulusay }\end{array}$ & 2007 & $\mathrm{~V}_{\mathrm{S}}=90 \mathrm{~N}^{0,309}$ \\
\hline 9 & Mina et al & 2010 & $\mathrm{~V}_{\mathrm{S}}=96,82 \mathrm{~N}^{0,34}$ \\
\hline 10 & Kirar et al & 2016 & $\mathrm{~V}_{\mathrm{S}}=99,5 \mathrm{~N}^{0,345}$ \\
\hline
\end{tabular}

Gambar 9 menunjukkan korelasi antara $V_{\mathrm{s}}$ dan $\mathrm{N}_{\text {SPT }}$ untuk semua jenis tanah dari penelitian dengan korelasi $\mathrm{V}_{\mathrm{S}}=98,759 \mathrm{~N}_{\mathrm{SPT}}{ }^{0,3101}$. Korelasi tersebut memiliki koefisien determinasi atau $\mathrm{R}^{2}$ sebesar 0,56 hal ini berarti bahwa pengembangan korelasi dengan menggunakan data (pengukuran langsung di lapangan) adalah memiliki estimasi $V_{s}$ yang cukup baik hal ini dapat dilihat dari nilai koefisien determinasi lebih besar 0,50. Korelasi antara variabel dependen dalam hal ini adalah parameter $V_{\mathrm{s}}$ dan varibel independen dalam hal ini parameter 
N SPT memiliki pengaruh yang kuat pada pengembangan korelasi.

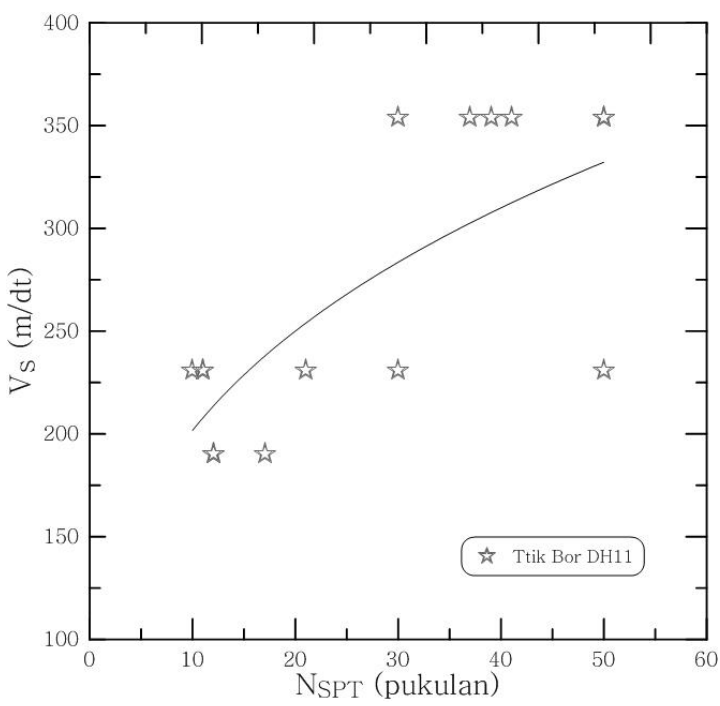

Gambar 9. Korelasi antara $\mathrm{V}_{\mathrm{s}}$ dan Nspt untuk semua jenis tanah.

Korelasi (antara $\mathrm{V}_{\mathrm{S}}$ dan $\mathrm{N}_{\mathrm{SPT}}$ ) yang diperoleh kemudian diplot kedalam grafik hubungan atara $\mathrm{V}_{\mathrm{s}}$ dengan kedalaman (Gambar 10). Pola antara $V_{s}$ dari korelasi memiliki kecenderungan yang sama dengan $V_{\mathrm{s}}$ hasil pengukuran MAM, ini berarti korelasi yang didapat mampu memprediksi $\mathrm{V}_{\mathrm{s}}$ dengan cukup baik.

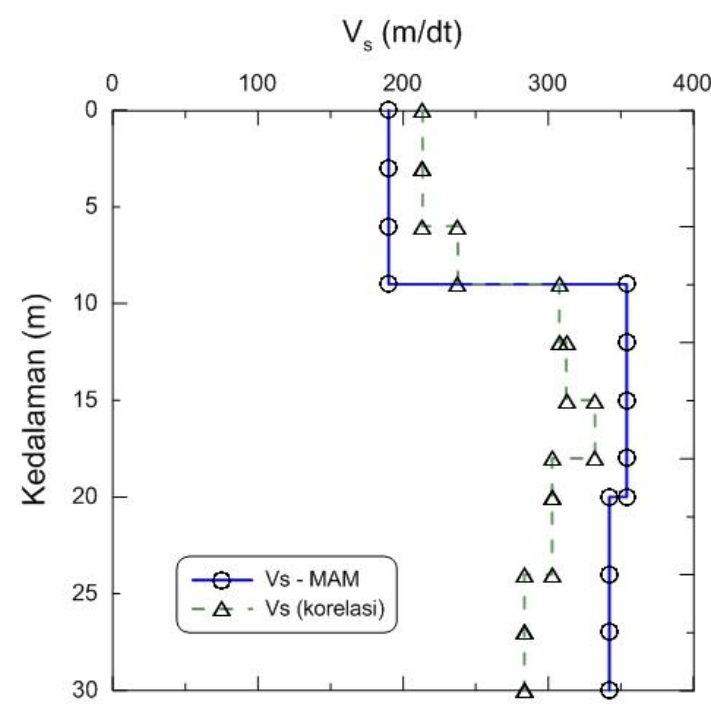

Gambar 10. Perbandingan $V_{s}$ dari Hasil MAM dan Hasil Korelasi (antara $V_{\mathrm{s}}$ dan $\mathrm{N}_{\mathrm{SPT}}$ ).

\section{KESIMPULAN}

Berdasarkan investigasi geoteknik dan geofisika telah dikembangkan korelasi antara
$\mathrm{V}_{\mathrm{S}}$ dengan $\mathrm{N}_{\text {SPT }}$ untuk semua jenis tanah di area pulau nuklir Tapak RDE, Serpong yaitu $\mathrm{V}_{\mathrm{s}}=$ $98,759 \mathrm{~N}_{\mathrm{SPT}}{ }^{0,3101}$. Korelasi ini mampu memprediksi $\mathrm{V}_{\mathrm{s}}$ dengan cukup baik dan cepat, tanpa harus melakukan pengukuran yang memerlukan biaya lebih banyak dan waktu lebih lama.

\section{UCAPAN TERIMA KASIH}

Penelitian ini didukung dan didanai oleh Pusat Kajian Sistem Energi Nuklir, Badan Tenaga Nuklir Nasional, (PKSEN - BATAN) Tahun Anggaran 2020.

\section{DAFTAR ACUAN}

[1] BATAN, "Site Evaluation Report on Geotechnical Aspect and Foundation at RDE Site, Serpong," Jakarta, 2016

[2] E. R. Iswanto, H. Suntoko, T. A. Ryanto, and A. Bondan, "Profil Gelombang Geser Area Reaktor di Tapak RDE, Serpong," in Seminar Nasional Infrastruktur Energi Nuklir, 2019, pp. 187-194.

[3] T. A. Ryanto, E. R. Iswanto, Y. Indrawati, A. B. W. Setiaji, and H. Suntoko, "Sediment Thickness Estimation in Serpong Experimental Power Reactor Site Using HVSR Method," J. Pengemb. Energi Nukl., vol. 22, no. 1, pp. 29-37, 2020.

[4] E. R. Iswanto, Y. Indrawati, and T. A. Riyanto, "Studi Mikrotremor dengan Metode HVSR di Tapak RDE, Serpong,” Eksplorium, vol. 40, no. 2, pp. 105114,2019

[5] A. Fauzi, M. Irsyam, and U. J. Fauzi, "Empirical correlation of shear wave velocity and N-SPT value for Jakarta," Int. J. GEOMATE, vol. 7, no. 1, pp. 980-984, 2014

[6] R. Luna and H. Jadi, "Determination of dynamic soil properties using geophysical methods," in First International Conference on the Application of Geophysical and NDT Methodologies to Transportation Facilities and Infrastructure, 2000, no. December, pp. 1-15.

[7] M. Esfehanizadeh, F. Nabizadeh, and R. Yazarloo, "Correlation between standard penetration (N $\mathrm{SPT}$ ) and shear wave velocity (V S) for young coastal sands of the Caspian Sea," Arab. J. Geosci., vol. 8, no. 9, pp. 7333-7341, 2014.

[8] Rix Glenn J et al., "Recent Advances in Surface Wave Methods for Geotechnical Site Characterization," in International Cnference on Soil Mechanics and Geotechnical Engineering, 2001, no. 3.

[9] J. A. Hunter et al., "Surface and downhole shear wave seismic methods for thick soil site investigations," Soil Dyn. Earthq. Eng., vol. 22, no. 9-12, pp. 931-941, 2002.

[10] M. K. Jafari, A. Shafiee, and A. Razmkhah, "Dynamic Properties of Fine Grained S oils in 
South of Tehran," J. Seismol. Earthq. Eng., vol. 4, no. $1,2002$.

[11] S. H. H. Lee, "Regression models of shear wave velocities in taipei basin," J. Chinese Inst. Eng., vol. 13, no. 5, pp. 519-532, 1990.

[12] ASTM, Standard Test Methods for Downhole Seismic Testing. 2008.

[13] Z. Zulfahmi and Z. Pulungan, "Assessment for Data Correlation of the Downhole Seismic Measurement Results on Underground Coal Gasification Location Using Multivariate Analysis," Indones. Min. J., vol. 18, no. 3, pp. 109-120, 2015.

[14] M. Sutrisna, C. Sulaeman, and N. D. Ardi, "Microtremor Methode for Microzonation in Cilacap City,” J. online Fis., vol. 3, no. 2, pp. 1-13, 2015.

[15] Gueguen et al, "An indication of the soil topmost layer response in Quito ( Ecuador ) using noise $\mathrm{H}$ / V spectral ratio," Soil Dyn. Earthq. Eng., vol. 19, pp. 127-133, 2000.

[16] Carniel et al, "Improvement of HVSR technique by wavelet analysis," Soil Dyn. Earthq. Eng., vol. 28, no. 4, pp. 321-327, 2008.

[17] Ü. Dikmen, "Statistical correlations of shear wave velocity and penetration resistance for soils," $J$. Geophys. Eng., vol. 6, no. 1, pp. 61-72, 2009.

[18] A. Ghazi, N. H. Moghadas, H. Sadeghi, M. Ghafoori, and G. R. Lashkaripur, "Empirical relationships of shear wave velocity, SPT-N value and vertical effective stress for different soils in Mashhad, Iran," Ann. Geophys., vol. 58, 2015.

[19] ASTM, Standard Test Method for Standard Penetration Test (SPT) and Split-Barrel Sampling of Soils, vol. D1586-11. 2011.

[20] B. Kirar, P. Muley, and B. K. Maheshwari, "Correlation Between Shear Wave Velocity ( Vs ) and SPT Resistance ( N ) for Roorkee Region," Int. J. Geosynth. Gr. Eng., vol. 2, no. 9, 2016.

[21] N. Hasancebi and R. Ulusay, "Empirical correlations between shear wave velocity and penetration resistance for ground shaking assessments," Bull. Eng. Geol. Environ., vol. 66, no. 2, pp. 203-213, 2007.

[22] E. Mina, "Korelasi Empiris Antara Kecepatan Gelombang Geser Dengan Nilai N SPT ( Studi Kasus Bandung Site )," J. Fondasi, vol. 1, no. 1, pp. 38-46, 2012. 